\title{
La Bioinformática y la Biología de Sistemas
}

COMUNICACIÓN

\section{Gabriela Paula Fernández}

Universidad Nacional del Noroeste de la Provincia de Buenos Aires, Argentina. Contacto: gabriela.fernandez@nexo.unnoba.edu.ar

\section{Pablo Daniel Ghiringhelli}

Universidad Nacional de Quilmes, Argentina. Contacto: pdg@unq.edu.ar

\section{Una caracterización}

La Bioinformática es una disciplina científica emergente, esencialmente multidisciplinaria, que puede ser caracterizada como una conjunción entre Biología, Bioquímica, Biofísica, Biotecnología, Matemática, Estadística, Computación, etc.

La Bioinformática participa activamente en la transformación de datos en información y, por tanto, puede ser considerada una Ciencia de la Información.

\section{La necesidad}

La Biología, la Bioquímica en todas sus expresiones, la Biofísica, la Biología Molecular, la Ingeniería Genética, y muchas otras áreas del quehacer "Biológico", en general son campos experimentales que en las últimas décadas han incrementado en forma exponencial la capacidad de recoger e interpretar datos en distintos niveles de organización, desde los sistemas hasta lo molecular.

Por ejemplo, en la actualidad, el conocimiento de los genomas de diferentes sistemas biológicos es técnicamente accesible en forma rápida y relativamente económica. Sin embargo, la información contenida en los mismos debe ser decodificada para alcanzar el conocimiento pleno y postular su empleo en distintas áreas de interés: salud, ambiente, agrobiotecnología, industria, etc.

La Bioinformática no sólo se involucra en el análisis de datos complejos usando herramientas computacionales. También aborda el diseño y mantenimiento de bases de datos a partir de la colección, organización y almacenamiento estructurado de la información biológica, concomitantemente con aportar a los procedimientos que permitan 
la accesibilidad y recuperación adecuada de la información biológica almacenada en las mismas.

No existe proceso "biológico" que no involucre etapas previas y/o posteriores de análisis bioinformático. Siendo, por tanto, un conocimiento imprescindible en la actualidad.

\section{El camino hacia la actualidad}

El conocimiento generado cotidianamente crece de manera exponencial, haciendo imposible que un individuo pueda abarcarlo en su totalidad. Actualmente, el conocimiento individual es reemplazado gradualmente por el conocimiento colectivo e interdisciplinario. Cualquier política que apunte a la excelencia debería promover la interrelación entre diferentes disciplinas, de manera que se aporten distintas visiones y se propongan soluciones novedosas. Resulta obvio que la Universidad es un ámbito ideal para promover una integración de este tipo.

En la década del 90, en la Facultad de Ciencias Exactas de la Universidad Nacional de La Plata se instala una MicroVax con el paquete de programas de análisis bioinformático conocido como UW-GCG (University of Winsconsin - Genetics Computer Group), al cual podían acceder usuarios externos empleando las tecnologías de comunicaciones de la época (por ejemplo, el modem telefónico).

En diciembre de 2002, organizado en forma combinada entre el IBBM (Instituto de Bioquímica y Biología Molecular, Facultad de Ciencias Exactas, Universidad Nacional de La Plata) y el LIGBCM (Laboratorio de Ingeniería Genética y Biología Celular y Molecular, Departamento de Ciencia y Tecnología, Universidad Nacional de Quilmes), se dicta un curso Internacional de Bioinformática financiado por: CABBIO (Centro Argentino-Brasileño de Biotecnología), ICSU (International Council for Science), RELAB (Red Latinoamericana de Ciencias Biológicas) y SECyT (Secretaría de Ciencia y Tecnología).

En 2003, en el IBBM (Fac. de Cs. Exactas, UNLP) se constituye Ar-EMBnet (Argentina-European Molecular Biology network), el primer nodo de EMBnet (European Molecular Biology network) en las Américas (actualmente se halla localizado en la Facultad de Ciencias Exactas y Naturales, Universidad de Buenos Aires).

En el año 2006 la Universidad Nacional de Entre Ríos es la primer universidad pública argentina en ofrecer la carrera de grado, la Licenciatura en Bioinformática.

En 2009, quince investigadores (uno del Instituto Leloir, uno de la Universidad Nacional de Bahía Blanca, uno de la Universidad Nacional de San Martín, uno de la Universidad Católica de Córdoba, dos de la Universidad Nacional de La Plata, cinco de la Universidad de Buenos Aires y cuatro de la Universidad Nacional de Quilmes) provenientes de diferentes áreas del conocimiento constituyeron la Asociación Argentina de Bioinformática y Biología Computacional (A2B2C, asociación científica sin fines de 
lucro) con el fin de promover la Bioinformática y constituirse en un núcleo de intercambio de conocimientos y capacidades.

En el año 2010 comienza a formularse el plan de estudios de la Licenciatura en Bioinformática en el Departamento de Ciencia y Tecnología de la UNQ. A mediados de 2014 se inicia oficialmente su dictado, constituyéndose en la segunda universidad pública argentina en ofertar esta carrera.

En 2011, en el contexto de la Red Argentino-Cubana de Bioinformática comienza a formularse una Maestría en Bioinformática y Biología de Sistemas, dictada conjuntamente por la Universidad Nacional de Quilmes (UNQ) y la Universidad Nacional del Noroeste de la Provincia de Buenos Aires (UNNOBA). Durante el segundo semestre de 2014 se inicia una primera cohorte de la Maestría en la sede Pergamino de la UNNOBA, y a principios de 2015 se inicia la primera cohorte en la UNQ. Ambas se encuentran actualmente en funcionamiento.

En paralelo con las actividades académicas, en diferentes entidades públicas del país, Universidades, INTA, Unidades Ejecutoras del CONICET, entre otras, se han ido generando grupos de investigación y desarrollo que trabajan en Bioinformática y Biología de Sistemas.

\section{El futuro}

El primer borrador de la secuencia del genoma humano (publicado en 2001; 3.000.000.000 de pares de bases) fue obtenido tras varios años de trabajo por parte de múltiples laboratorios y con un costo de miles de millones de dólares. No obstante, los desarrollos tecnológicos interdisciplinarios de las últimas dos décadas han permitido que hoy se puedan obtener los mismos datos en 7 a 10 días de trabajo intensivo y con un costo que tiende a estar entre U\$ 1.000-3.000. Esto demuestra que secuenciar un genoma ya ha dejado de ser una utopía para constituirse en una realidad cotidiana. Los costos en tiempo y dinero guardan relación con la dimensión del genoma incógnita. Así, obtener los datos de secuencia de un genoma bacteriano implica como mucho un día de trabajo y alrededor de U\$S 150-250.

La obtención de datos genómicos es un primer paso en el paradigma de la era postgenómica. Su disponibilidad abre múltiples caminos posibles de aplicación:

- Introducir mejoras en los procesos de producción de alimentos (un mejor análisis del suelo unido a métodos innovadores de agricultura de precisión proveerán una mejor comprensión y diagnóstico acerca de qué cultivar y dónde);

- Realizar una selección rápida de variedades de organismos de interés agropecuario (el análisis de los genomas podrá brindar información directa de los cambios relacionados con genes específicos); 
- Diseñar nuevas estrategias para el control de plagas (atacar puntos débiles de vías metabólicas particulares del ciclo de vida de un patógeno con productos de alta especificidad diseñados a partir de la química combinatoria y/o diseñar agentes virales optimizados para el control biológico);

- Desarrollar procesos industriales amigables con el ambiente (utilizar microorganismos modificados y/o conjuntos de enzimas específicas que permitan optimizar las producciones, generando menos productos secundarios perniciosos y/o utilizar microorganismos modificados y/o conjuntos de enzimas específicas que permitan aprovechar rezagos de otras industrias para generar productos y agregar valor);

- Desarrollar procesos enzimáticos de remediación ambiental (uso de enzimas recombinantes optimizadas molecularmente);

- Estudiar la biodiversidad de especies, así como de sus ambientes, a diferentes escalas temporales;

- Iniciar el camino hacia una medicina personalizada (del genoma al diagnóstico predictivo y del genoma a una selección óptima de drogas y terapias);

- Etc.

El detalle previo no agota las posibilidades futuras constituyéndose en un devenir continuo. Sin embargo, en este punto es importante destacar que hace falta un perfil profesional con la capacidad, no sólo de procesar y gestionar grandes cantidades de datos, sino también de saber interpretarlos. En este sentido, la Bioinformática tiene un papel fundamental, tanto desde la formación de grado como desde la formación de posgrado, complementaria de perfiles previos. 